\title{
Design and testing of an unlimited field-of-regard synthetic vision head-worn display for commercial aircraft surface operations
}

\author{
J.J. (Trey) Arthur III ${ }^{* a}$, Lawrence Prinzel III ${ }^{\mathrm{a}}$, Kevin Shelton ${ }^{\mathrm{a}}$, Lynda J. Kramer ${ }^{\mathrm{a}}$, \\ Steven P. Williams ${ }^{\mathrm{a}}$, Randall E. Bailey ${ }^{\mathrm{a}}$, Robert M. Norman ${ }^{\mathrm{b}}$ \\ ${ }^{a}$ NASA Langley Research Center, Hampton, VA 23681-2199 \\ ${ }^{\mathrm{b}}$ Boeing Phantom Works, Hampton, VA 23669
}

\begin{abstract}
Experiments and flight tests have shown that a Head-Up Display (HUD) and a head-down, electronic moving map (EMM) can be enhanced with Synthetic Vision for airport surface operations. While great success in ground operations was demonstrated with a HUD, the research noted that two major HUD limitations during ground operations were their monochrome form and limited, fixed field of regard. A potential solution to these limitations found with HUDs may be emerging Head Worn Displays (HWDs). HWDs are small, lightweight full color display devices that may be worn without significant encumbrance to the user. By coupling the HWD with a head tracker, unlimited field-of-regard may be realized for commercial aviation applications. In the proposed paper, the results of two ground simulation experiments conducted at NASA Langley are summarized. The experiments evaluated the efficacy of head-worn display applications of Synthetic Vision and Enhanced Vision technology to enhance transport aircraft surface operations. The two studies tested a combined six display concepts: (1) paper charts with existing cockpit displays, (2) baseline consisting of existing cockpit displays including a Class III electronic flight bag display of the airport surface; (3) an advanced baseline that also included displayed traffic and routing information, (4) a modified version of a HUD and EMM display demonstrated in previous research; (5) an unlimited field-of-regard, full color, head-tracked HWD with a conformal 3-D synthetic vision surface view; and (6) a fully integrated HWD concept. The fully integrated HWD concept is a head-tracked, color, unlimited field-of-regard concept that provides a 3-D conformal synthetic view of the airport surface integrated with advanced taxi route clearance, taxi precision guidance, and data-link capability. The results of the experiments showed that the fully integrated HWD provided greater path performance compared to using paper charts alone. Further, when comparing the HWD with the HUD concept, there were no differences in path performance. In addition, the HWD and HUD concepts were rated via paired-comparisons the same in terms of situational awareness and workload. However, there were over twice as many taxi incursion events with the HUD than the HWD.
\end{abstract}

Keywords: Synthetic Vision, Head-Worn Displays, Helmet-Mounted Displays, Surface Operations

\section{INTRODUCTION}

The Integrated Intelligent Flight Deck Technologies (IIFDT) project, under NASA's Aviation Safety Program (AvSP), comprises a multi-disciplinary research effort to develop flight deck technologies that mitigate operator-, automation-, and environment-induced hazards. Towards this objective, IIFDT is developing crew/vehicle interface technologies that reduce the risk of pilot error, improve aircraft safety for current and future civilian and military aircraft, and proactively overcome aircraft safety barriers that would otherwise constrain the full realization of the Next Generation Air Transportation System (NGATS). Part of this research effort involves the use of synthetic and enhanced vision systems and advanced display media as enabling crew-vehicle interface technologies to meet these safety challenges.

The NTSB continues to have runway incursion prevention on its top six most wanted list for aviation safety. In a typical year, 300 to 400 runway incursion events are reported. These events are cause for alarm as the worst aviation accident in terms of fatalities occurred in 1977 when two fully loaded 747 airplanes collided on a runway at Tenerife airport. Moreover, each year there are reports of close "near-miss" runway incursions that happen with sufficient regularity at the world's busiest airports to pose perhaps the most significant hazard confronting aviation today. One

* Trey.Arthur@nasa.gov, NASA LaRC, 24 W Taylor Street, Hampton, VA 23681, phone 17578646609 
such airport plagued with runway incursions is Chicago O’Hare International Airport (FAA identifier: ORD). Chicago O'Hare is a complex airfield for surface operations and represents one of the world's busiest and most challenging airports for surface operations. The ORD airport authority has identified "hot spots" which are areas where incursions are likely to occur. Ground traffic and aircraft handling are also designed so that nominal operations minimize incursion potential. ORD has an Airport Movement Area Safety System (AMASS) which is used to warn of incursions, but even with these protocols and technology implementations, there have been several recent close calls. For example, there was a runway incursion between two Boeing 747s at O'Hare on April 1, 1999. From the NTSB meeting on June 13, 2000:

"On April 1, 1999, just after 2 o'clock in the morning, Korean Air flight 36 and Air China 9018, both Boeing 747s, nearly collided on runway 14 Right at the Chicago O'Hare International Airport. Air China had just landed and was rolling out on runway 14 right when the tower controller instructed Korean Air to taxi into position and hold. After Air China exited the runway at taxiway T10, the tower controller instructed the flight to turn left on taxiway Kilo and cross runway 27 left. The tower controller then cleared Korean Air for takeoff. As the airplane was rolling down the runway, Air China deviated from its assigned taxi route and taxied on to runway 14 Right. The Korean Air captain saw the 747 taxiing on to the runway but it was too late to stop. Instead, Korean Air 36 lifted off earlier than normal and banked left to avoid striking Air China. The two aircraft, carrying 382 people, missed colliding by about 80 feet."

The potential consequences of such runway incursions have prompted NASA to initiate research to reduce the increasing rate of runway incursions. NASA has been conducting research into runway incursion prevention systems for a number of years with great success in demonstrating that a flight deck alerting capability has significant potential to reduce, if not eliminate, runway incursions in the future. The present study was an extension of that research with the objective to determine whether providing an unlimited field-of-regard, color synthetic view could further enhance the efficacy already demonstrated in a prior system with an advanced head-down moving map display combined with a HUD. In this paper, none of the display concepts had incursion alerting capability.

\subsection{Head Worn Displays (HWD)}

Advances in display devices (e.g., head-worn devices) have been studied by NASA researchers as an alternate and practical method for delivering SVS concepts to the cockpit ${ }^{1}$. HWDs are small, light weight full color display devices that can be worn on the head without significant encumbrance (Fig. 1). By coupling the HWD with a head tracker, unlimited field-of-regard can be realized. Unlike fixed field of view (FOV) sensors, the camera position and orientation for Synthetic Vision can be defined via software; thus, an unlimited field-of-regard is achieved since the Synthetic Vision scene is viewable from any virtual camera angle.

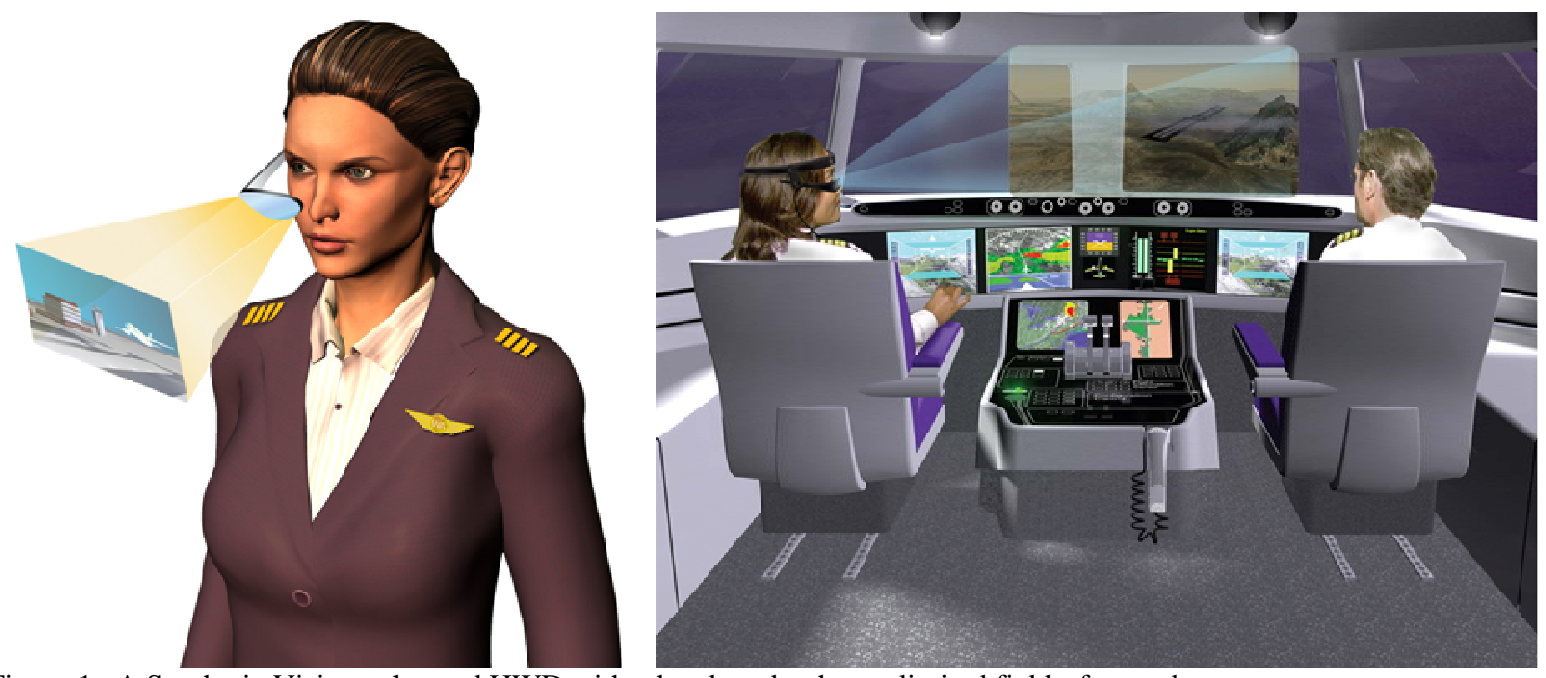

Figure 1. A Synthetic Vision enhanced HWD with a head tracker has unlimited field-of-regard. 
The advantages of the full color, Head Tracked - Head Worn Display (HT-HWD) can directly address the HUD limitations shown in RIPS ${ }^{2}$ and T-NASA ${ }^{3,4,5,6}$ testing. As such, a study was conducted to determine the efficacy of a HT-HWD in a complex taxiing task in a fixed-based simulator. In addition, the study was used to obtain pilot comments on the concept and future enhancements required for using a HT-HWD for surface operations.

\subsection{Experiment studies}

Two experimental studies were conducted to determine the efficacy of using HWDs to enhance taxi operations. For both experiments, full-color HWD display concepts were evaluated in surface operations to address previously witnessed display technology limitations. Previous research has shown that a HUD can significantly enhance situational awareness (SA) for surface operations; however, due to the HUD's fixed field-of-regard and limited FOV, intuitively portraying turns on the HUD can be difficult ${ }^{4}$. Further, information clutter is a driving constraint for the monochromatic HUD.

\subsection{Simulation facility}

Both studies were conducted in the Research Flight Deck (RFD) simulator at NASA LaRC. The RFD is a stationary, dual-pilot simulator consisting of a collimated 200-degree out-the-window visual. The RFD is equipped with a $30^{\circ} \mathrm{H} \mathrm{x}$ $24^{\circ} \mathrm{V}$ HUD on the captain's side. The HWD, worn only by the captain, was an $800 \mathrm{H} \mathrm{x} 600 \mathrm{~V}$ pixel, full color display with see-through capability, $60 \mathrm{~Hz}$ refresh and a pilot selectable brightness knob. The subject pilots placed the HWD over the right eye so that it was visible by glancing up, and therefore, subject pilots maintained unimpeded stereoscopic vision for out-the-window monitoring. An optical head tracker provided the head orientation data. The RFD has 8 Size D (6.4 inch square viewable area) head-down displays: captain and first officer primary flight displays (PFD) and navigation displays (ND), two engine displays on the center aisle and two outboard auxiliary displays. For both experiments, the first officer's outboard auxiliary display was used as a repeater display of the captain's head-up display. The pilot controls were a tiller, throttles, rudder pedals (nose wheel steering) and differential toe brakes. The simulated aircraft for both experiments was a Boeing 757.

\section{EXPERIMENT ONE: TAXI OPERATIONS WITH ADVANCED DISPLAY}

\subsection{Methodology}

\subsubsection{Evaluation pilots}

Sixteen commercial flight crews (a captain and first officer) participated in the experiment. Each flight crew flew for the same company to ensure crew coordination and cohesion with regard to surface operation procedures. The captains had an average of over 16,000 flight hours with 22.3 years of commercial flying and the first officers had an average of over 11,000 flight hours with 13.5 years of commercial flying. Forty-four percent of subject captains required corrective lenses. The subjects were given a 45-minute briefing to explain the display concepts and the evaluation tasks. After the briefing, a 1-hour training session was conducted to familiarize the subjects with the RFD simulator, HUD, the HWD device, and the piloting task. Only the captain had a HUD or HWD; the first officer had a head-down repeater display of the captain's head-up device. An eye dominance test was performed after the training briefing. All subject captains were right eye dominant. The HWD was viewed with the right eye. Following training, 5 hours of data collection was conducted. The total experiment time for a subject crew was approximately 8 hours.

\subsubsection{Evaluation task}

Pilots conducted taxi operations at Chicago O’Hare International Airport. The display concept and weather were varied. A total of 27 different taxi scenarios were used in the study. All taxiing tasks involved exiting the runway and taxiing to the airport movement area. The weather state for the out-the-window scene was varied between night-time with unlimited visibility (visual meteorological conditions; VMC), and daytime with 700 -foot runway visibility range (RVR). For the final run, the visibility was reduced to 500-foot RVR. Pilots were instructed to taxi at a speed they thought appropriate for the task and to avoid other aircraft. The subject crews were briefed to follow their company guidelines as far as taxi speeds and procedures. Further, crews were instructed that the safety of the aircraft should never be compromised. 
Before each data trial, the flight crews were briefed on their current location and expected turnoff. Each trial began with an initial speed of 10 knots followed by an immediate call from the tower controller. Once cleared of the runway, the first officer switched to ground frequency and called the ground controller for clearance. The ground controller provided the ground clearance along with a data linked message of the route. During the data run, automated air traffic control (ATC) communications were played to simulate typical radio party line chatter. In addition, other pre-recorded aircraft traffic taxied around the surface. Crews were instructed that the traffic was pre-recorded; therefore, they should give way to all traffic. Further, they were briefed that the ground controller would not provide traffic awareness cues.

\subsubsection{Display concepts}

Four different display concepts were used (Fig. 2):

1) A head-down electronic moving map (EMM) without routing or traffic information. There was no head-up display with this concept (Baseline),

2) A HWD concept with a head tracker that displayed a virtual airport environment but no traffic, routing or clearance information with the baseline EMM head-down display (Intermediate HWD),

3) A HUD concept with an advanced EMM head-down display. The scene-linked HUD symbology consisted of 3-dimensional depiction of the cleared route by highlighting the taxiway edge lines and centerlines. The advanced EMM contained iconic traffic, clearance and routing information (Advanced HUD) and

4) An advanced HWD concept with virtual traffic and routing information and an advanced EMM head-down display (Advanced HWD).

All display concepts had a head-down EMM display. The EMM consisted of a perspective, track-up view of the airport showing an ownship symbol, ground speed, heading, surface movement areas, centerlines, airport surface labels, and current range selection. Both the captain and first officer had an EMM display with independent range controls, which consisted of 4 zoom levels. The EMM replaced the navigation display (ND). In addition to the perspective track-up mode, the pilot could select a north-up mode that showed the entire airport view from directly above.

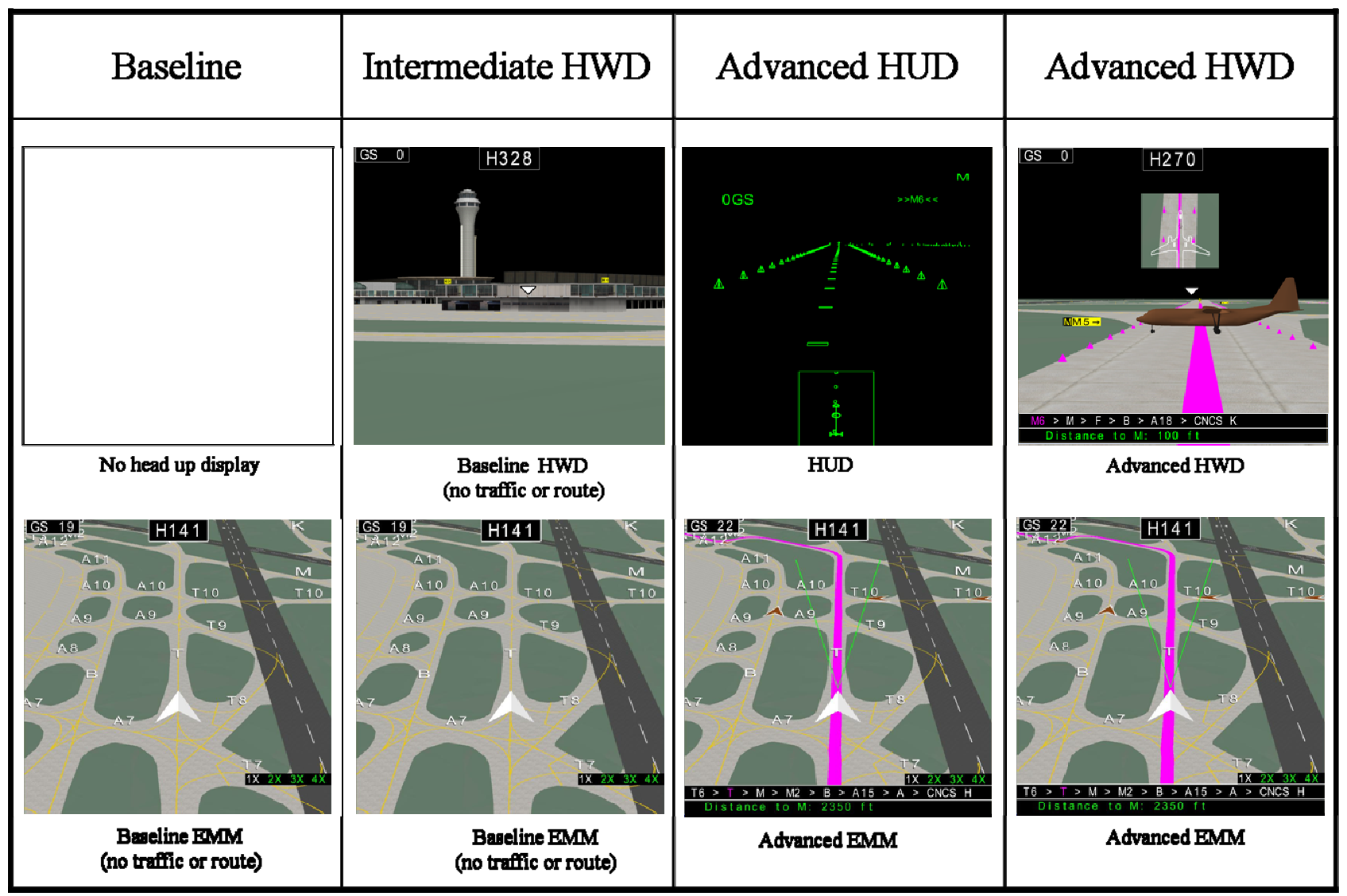

Figure 2. The four display concepts: Baseline, Intermediate HWD, Advanced HUD and Advanced HWD. 
Two EMM display concepts were used: 1) a baseline EMM that contained an ownship symbol, ground speed, heading, taxiways with centerlines and labels and runways, and 2) an advanced EMM. The advanced EMM contained the same information as the baseline EMM with the addition of a route display, clearance information, distance to the next taxiway, and traffic icons. For the advanced display concepts (Advanced HUD and Advanced HWD), symbology was displayed on the EMM that depicted the field-of-view of the head-up device. On the advanced EMM shown in Fig. 2, the field-of-view symbology is shown as green wedge-shaped lines on the ownship symbol. For the HUD, the angle of the wedge symbology was 30 degrees, as this is the horizontal field-of-view of the HUD. For the HWD concepts, wedge symbology was 22 degrees. Also, this field-of-view symbology moved as the captain moved his/her head; thus, the portion of the virtual airport the captain was viewing could be correlated on the EMM. Hold short symbology was a typical roadside stop sign.

The intermediate display concept consisted of the baseline EMM head-down display and the HWD with head tracker. The HWD was a virtual airport view from the pilot's eye perspective. The virtual world was aligned manually by the captain by slightly tilting his/her head down making the out-the-window view and virtual airport view conformal, thus the actual taxiways overlaid the virtual taxiways. The virtual airport consisted of the ORD airport, buildings, surface movement areas and centerlines. Taxi signage was displayed in the HWD. This signage was modeled to appear to be actual airport surface signage; however, the HWD signage was placed on the side of an upcoming turn and did not necessarily correlate with the actual out-the-window sign placement. The HWD displayed the ground speed, heading and an aircraft-heading pointer. The aircraft-heading pointer was used to aid the pilot in determining the aircraft heading during head movement.

The Advanced HUD display concept was based on RIPS ${ }^{2}$ and T-NASA ${ }^{3}$ concepts (Fig. 3). The head-up display showed current ground speed in digital format, the current taxiway (shown as M6 in Fig. 3), next cleared taxiway (shown as M in upper right of Fig. 3), centerline markers and virtual cones on the taxiway edge. Additional cues were given for turns. These cues consisted of turn flags and virtual turn signs (similar to roadway turn signs) ${ }^{7}$. Runway holding positions were displayed as a single solid line at the hold short locations. Also, a virtual stop sign was placed in the middle of the hold short line. A non conformal taxi director display provided an intuitive display of the relationship between the taxiway centerline and the aircraft's landing gear. The captain could remove all the symbols from the HUD display by pressing the auto throttle disconnect button. The auto throttle disconnect button was used for declutter because it was conveniently located and auto throttles were not used in the experiment. A second press of the auto throttle disconnect would restore all of the HUD symbology. The captain also had control of the brightness level of the HUD.

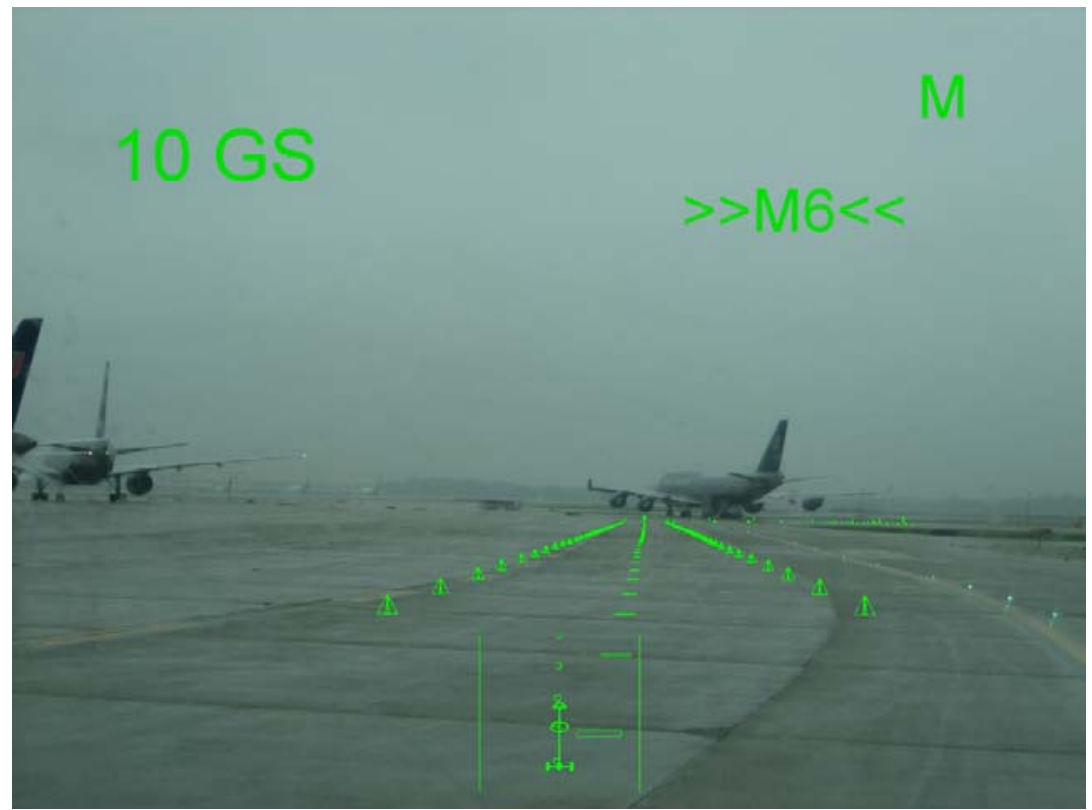

Figure 3. HUD showing centerline and edge line cones of the cleared route. Bottom box shows the taxi director non conformal display. 
The Advanced HWD concept contained all of the information in the Intermediate HWD concept with addition of traffic and routing information. The Advanced HWD employed a 3-dimensional generic aircraft model to depict traffic, the cleared route was shown as a magenta overlay on the taxiway centerline, text was displayed for the cleared route and for the distance to the next taxiway, and virtual taxiway edge cones depicted the edge lines of the cleared route. Like the HUD, virtual turn signs were used as an additional turn cue and hold short cues were denoted by virtual stop signs. Similar to the HUD, a non-conformal insert depicted a plan view of the runway, together with the airplane outline and location of the gear (Fig. 4). The pilot could remove this non-conformal display by pressing the auto-throttle disconnect button. A second press of the auto-throttle disconnect button would remove all symbology in the HWD. A third press would bring all symbology back to the HWD. Also, the captain could control the brightness of the display via a rotary knob.

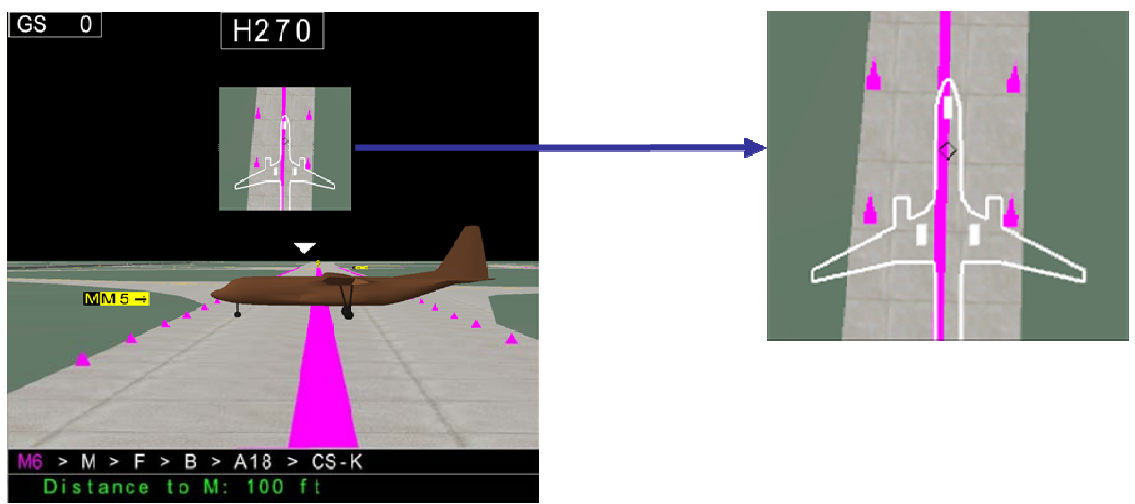

Figure 4. The non-conformal insert display. Shown in the insert are the ownship outline, main gear, nose gear and route.

\subsection{Experiment One results}

\subsubsection{Quantitative data}

\subsubsection{Taxi Performance}

A Multi-Variate Analysis of Variance (MANOVA) Will's Lambda test revealed a significant main effect for display concept, $\mathrm{F}(9,585)=4.755$, $\mathrm{p}<0.0001$; and visibility condition, $\mathrm{F}(9,240)=6.221, \mathrm{p}<0.0001$. For display condition, subsequent tests of general linear model univariate effects showed significant effects for taxi speed $F(3,242)=6.253$, $\mathrm{p}$ $<0.01$; and RMS path error $\mathrm{F}(3,242)=5.128, \mathrm{p}<0.01$. No significant effects were found for time to taxi, $\mathrm{p}>0.05$. For RMS path error, post-hoc Student Newman-Keuls test reported two unique subsets: (1) Advanced HUD and Advanced HWD produced significantly lower RMS path error than both Baseline and Intermediate HWD, but they were not statistically significant from each other; and (2) no significant differences between Intermediate HWD and Baseline condition (Fig. 5). For taxi speed, three overlapping subsets were found, in order of reduced mean taxi speed: (1) Advanced HUD and Advanced HWD; (2) Advanced HWD and Intermediate HWD, and (3) baseline and Intermediate HWD (Fig. 5).

For visibility, the ANOVA found a significant effect for time to taxi, $F(1.242)=4.452, \underline{p}<0.01$; and taxi speed, $F(1,242)$ $=10.518, \underline{\mathrm{p}}<0.01$. No significant effects were found for RMS path error, $\mathrm{p}<0.05$. Flight crews taxied significantly faster (15 kts vs. $13 \mathrm{kts})$ and took less time to taxi (219 sec vs. $233 \mathrm{sec}$ ) to the airport movement area during the 700 RVR visibility than the night VMC condition, respectively. The interaction between display condition and visibility condition was not significant, $\mathrm{p}>0.05$.

\subsubsection{Navigational errors}

Navigational errors were divided into 2 categories: major and minor ${ }^{5}$. A major navigation error is defined as a loss of navigational awareness, which resulted in a wrong turn or a failure to turn. A minor navigation error is defined as failure to remain on route but was immediately noticed and corrected by the crew. A navigation error, which involved an incursion with other aircraft, was accounted for in a different measure and not included as a navigational error. A 
total of 34 navigational errors were made, where 22 were classified as major errors and 12 were classified as minor. All of the major errors occurred with the Baseline and Intermediate HWD concept. Figure 6 shows the navigational errors made per display concept and weather event (night VMC or day 700 RVR).

\subsubsection{Taxi incursions}

A taxiway incursion event was defined as a collision with another aircraft or making a turn in front of another aircraft and creating a close call. A total of 18 incursion events occurred with a third of those events occurring with the HUD concept (Fig. 6).

\subsubsection{Rare events}

Of the 27 different runs that each flight crew experienced, three data runs were rare-event scenarios. These rare-event scenarios occurred in the data trials based on the severity of the rare-event. High severity rare-events occurred late in the data trials as to not confound other experimental runs ${ }^{8}$. All 16 subject crews experienced each of the 3 rare events only once.

The first rare event represented an ATC error in which the controller verbally instructed the pilots to turn right even though the ground controller's up-linked route depicted a left turn. The results from this trial showed that all crews that did not have a route displayed, either on the EMM or HWD device, turned the wrong way on the intended route. Crews with the displayed route immediately called ground and asked for clarification before making the turn.

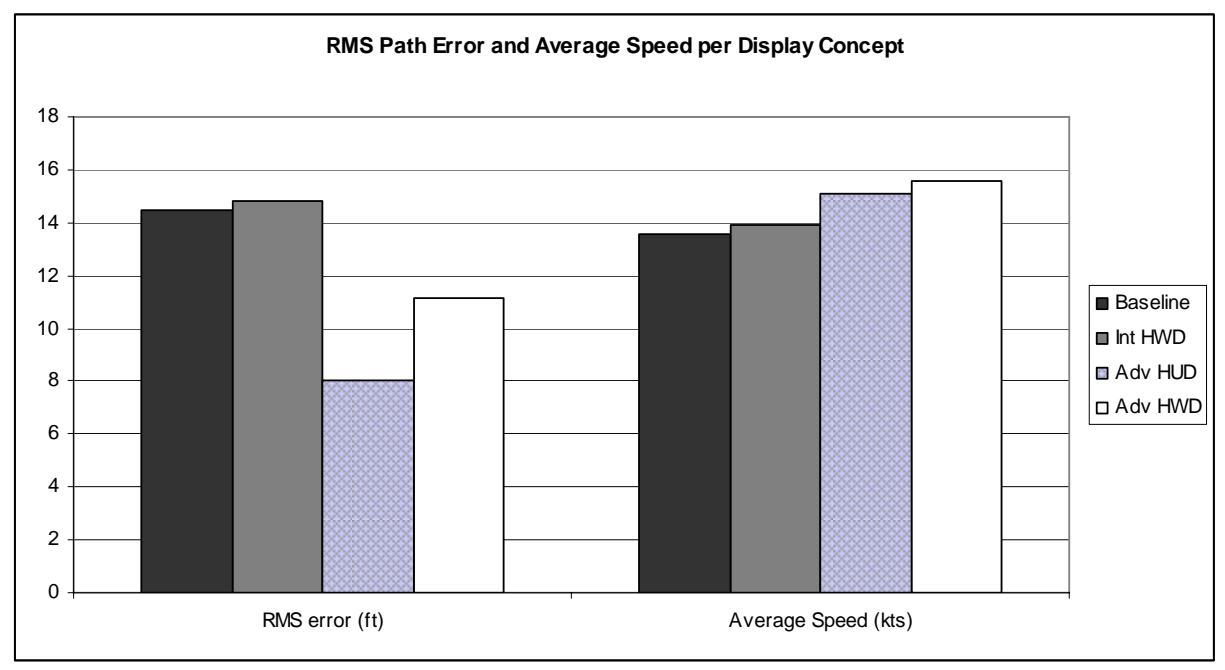

Figure 5. RMS Path Error and Taxi Speed for Display Condition

The second rare event had traffic that was not broadcasting its position, thus, the non-transponding traffic did not appear on the head-down EMM or the advanced HWD. The non-transponding aircraft did not cause an incursion event but was obvious enough to be easily detected in the out-the-window scene. Neither the Baseline concept nor the Intermediate HWD concept was included as a display condition for this rare event because traffic is not displayed on these concepts. All crews noticed the traffic out-the-window and 9 of the 16 crews noticed the traffic was not displayed head-down. The remaining 7 crews did not notice that the traffic was not displayed on the EMM or the advanced HWD.

The final rare event and final run of the day created a potential nose-to-nose traffic incursion. The nose-to-nose rare event was designed to provide insight into traffic awareness between the different display concepts. A common occurrence at ORD is when the terminal area is congested, aircraft may be given a "double back" clearance to create spacing and clear other taxiways. This event did not create a collision scenario but instead represented a more likely and common situation where two aircraft were "stuck" which would require an aircraft tug to separate the two airplanes. A nose-to-nose situation can significantly reduce airport efficiency to resolve the incursion (FAA Class D level incursion). For this rare event, crews were given a ground controller instruction for them to turn onto a taxiway that was occupied by another aircraft (a small commuter jet). The visibility was reduced to 500 foot RVR for this scenario 
so that the traffic was difficult to see, but detectable out-the-window. The incurring aircraft was on the left (captain's) side. The scenario also had 2 aircraft on the first officer's side. To further increase the workload of the first officer, a complex ground clearance was given close to the incursion point. Therefore, the prevention of the nose-to-nose situation depended mostly on the captain's awareness.

The rare event display condition was evenly distributed between each of the 4 display concepts; therefore each of the 4 display concepts had 4 rare event data points. For display concepts that did not have path or traffic information (Baseline and Intermediate HWD), 7 of the 8 crews were not able to avoid a nose-to-nose condition. One of these flight crews was able to turn out of the nose-to-nose as they noticed the traffic before fully committing to the turn. For the display concepts that had iconic traffic display (Advanced HUD and Advanced HWD), all but 2 crews were able to avoid the nose-to-nose situation. Both nose-to-nose conditions occurred with the Advanced HWD concept. Exit interviews with these flight crews revealed that the traffic represented on the HWD was not discernable because the aircraft was colored brown to conform with TCAS color symbology convention. One reason for conducting Experiment Two (discussed below) was to identify the significance of this limitation.
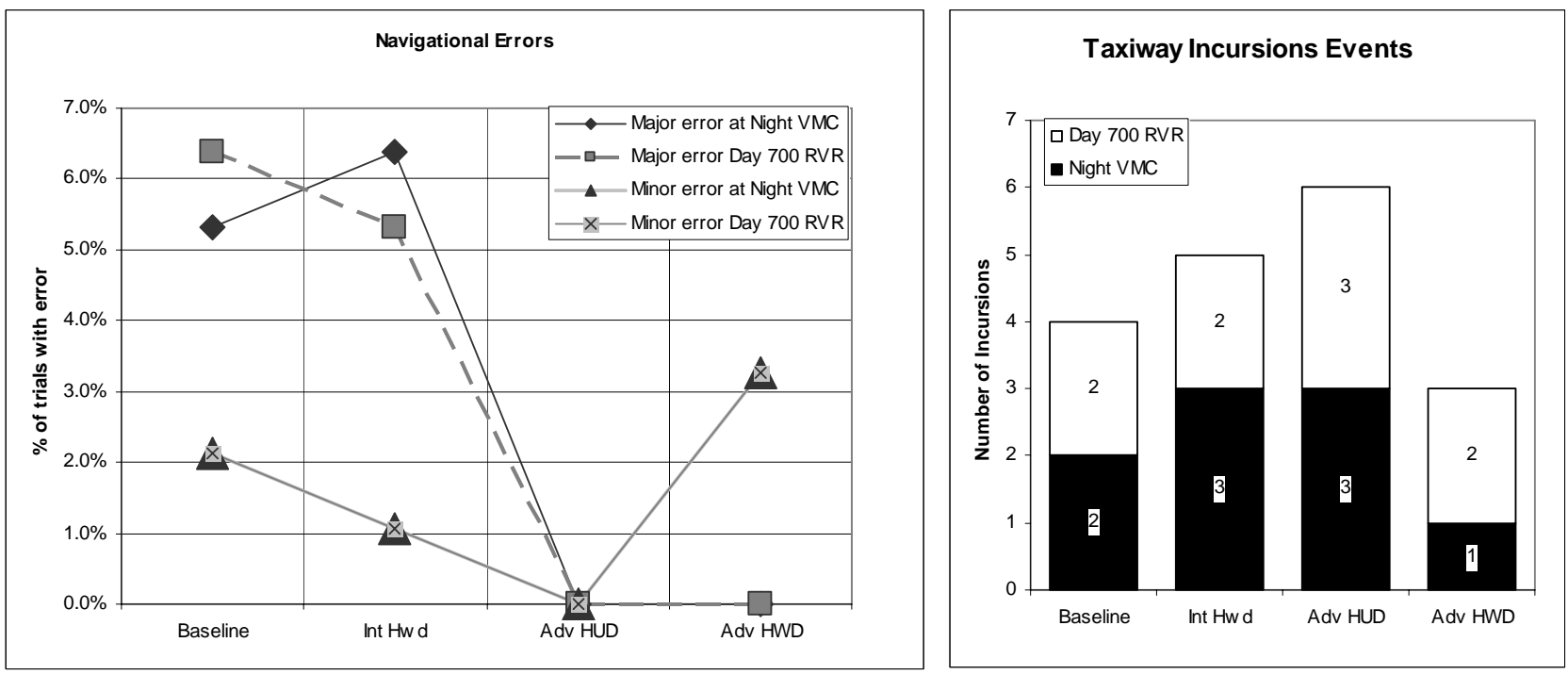

Figure 6. Navigational and incursion errors per display concept and weather event.

\subsubsection{Qualitative data}

Several questionnaires were given at the end of each data run. At the end of the day, paired-comparison questionnaires were given to both the captain and first officer.

\subsubsection{Post-run}

\subsection{NASA TLX}

An ANOVA was performed for the dependent variable of task load index (mental workload) from flight crew ratings on the NASA Task Load Index (NASA-TLX) scale ${ }^{9}$. No significant differences were found, $\mathrm{p}<0.05$.

\subsection{SART}

An ANOVA was performed for the dependent variable of situation awareness derived from flight crew ratings on the Situation Awareness Rating Technique $(\mathrm{SART})^{10}$. SA = Understanding - (Demand - Supply). Analysis found a significant effect for display condition, $\mathrm{F}(3,15)=4.16, \mathrm{p}<0.05$. A Student Newman-Keuls test revealed two unique subsets: (1) Advanced HWD (133.04) and Advanced HUD (130.23) - highest SA; and, (2) Baseline (104.07) and Intermediate HWD (112.30) - lowest SA. The SA provided by the Advanced HWD and Advanced HUD was not significantly different from each other nor were the Baseline and Intermediate HWD significantly different from each other. 


\subsection{Taxi situational awareness questions}

Flight crews were administered a Likert post-run experimental questionnaire ( 1 to 5 scale; 1 = "not at all"; 5 = "very much") to rate the display conditions contribution to taxi efficiency, overall navigation awareness, route awareness of local controller clearance, route awareness of ground controller clearance, surface traffic awareness, directional awareness, and taxi safety. An ANOVA revealed significant effects for all dependent variables, $\mathrm{p}<0.05$. Post-hoc Student Newman-Keuls tests were performed on these dependent variables resulting in two unique subsets: (1) no significant differences between Advanced HUD and Advanced HWD, and (2) no significant differences between Intermediate HWD and Baseline. Means for each dependent variable are presented in Table 1.

Table 1. Means for Post-Run Questionnaire By Display Condition

\begin{tabular}{|c|c|c|c|c|c|c|c|}
\hline & $\begin{array}{c}\text { Taxi } \\
\text { Efficiency }\end{array}$ & $\begin{array}{c}\text { Navigation } \\
\text { Awareness }\end{array}$ & $\begin{array}{c}\text { Route } \\
\text { Awareness } \\
\text { (local) }\end{array}$ & $\begin{array}{c}\text { Route } \\
\text { Awareness } \\
\text { (Ground) }\end{array}$ & $\begin{array}{c}\text { Traffic } \\
\text { Awareness }\end{array}$ & $\begin{array}{c}\text { Direction } \\
\text { Awareness }\end{array}$ & Taxi Safety \\
\hline \hline Baseline & 3.56 & 3.62 & 3.62 & 3.47 & 2.62 & 3.17 & 3.49 \\
\hline $\begin{array}{c}\text { Intermediate } \\
\text { HWD }\end{array}$ & 3.63 & 3.67 & 3.72 & 3.59 & 2.81 & 3.26 & 3.58 \\
\hline $\begin{array}{c}\text { Advanced } \\
\text { HWD }\end{array}$ & 4.49 & 4.46 & 4.35 & 4.42 & 3.9 & 3.76 & 4.42 \\
\hline $\begin{array}{c}\text { Advanced } \\
\text { HUD }\end{array}$ & 4.56 & 4.48 & 4.37 & 4.43 & 4.04 & 3.82 & 4.44 \\
\hline
\end{tabular}

\subsection{Simulation sickness questionnaire}

HWDs have been found to induce symptoms of motion or simulator sickness. The potential causes are many ${ }^{11}$. The occurrence of simulator sickness in operation or training with HWDs for commercial aviation applications would be problematic and detrimental to the commercial applications of HWDs if this were the case ${ }^{12}$. At the end of each run, pilots were given a questionnaire to determine simulation sickness ${ }^{13}$. Crews were also given a baseline and an end-ofthe-day questionnaire. Detailed results are discussed in SPIE Defense and Security Symposium paper 6557-31 by Bailey, et al in the Head-/Helmet-Mounted Displays XII conference, April 2007.

\subsubsection{Post-test}

\subsection{Paired comparisons}

A MANOVA statistical procedure was performed on four paired comparison scales administered to the captain and first officer of each flight crew; however, for brevity, only the captain's results are reported in this paper. The paired comparison scales asked the pilot to factorial evaluate each of the four display concept in comparison to one another on four constructs: Situation Awareness (SA-SWORD) ${ }^{14}$, Mental Workload (SWORD), Taxi Efficiency, and Taxi Safety. The analyses were conducted separately for captain and first officer responses. Significant results reported are at the $\mathrm{p}$ $<0.01$ significance level.

There was a significant main effect found for situation awareness, $F(3,45)=54.49$. A post-hoc test revealed (a) the moving map display to be significantly lower in situation awareness than the other three display concepts; (b) the Intermediate HWD to be significantly lower in situation awareness than the Advanced HUD and Advanced HWD; and (c) no significant differences between the Advanced HUD and Advanced HWD concepts.

There was a significant main effect found for mental workload, $F(3,45)=5.28$ A post-hoc test revealed (a) the Advanced HUD and Advanced HWD to be significantly lower in Mental Workload than both the Intermediate HWD and moving map display which (b) were not significantly different from each other and (c) no significant differences between the Advanced HUD and Advanced HWD concepts. 
There was a significant main effect found for taxi efficiency, $F(3,45)=23.655$. A post-hoc test revealed (a) the Advanced HUD and Advanced HWD to be significantly better for taxi efficiency than both the Intermediate HWD and moving map display which (b) were not significantly different from each other and (c) no significant differences between the Advanced HUD and Advanced HWD concepts.

There was a significant main effect found for taxi safety, $F(3,45)=23.859$. Post-hoc tests revealed (a) the Advanced HUD and Advanced HWD to be significantly higher in reported surface operations and taxiing safety than both the Intermediate HWD and moving map display which (b) were not significantly different from each other, and (c) no significant differences between the Advanced HUD and Advanced HWD concepts.

\subsection{Discussion of Experiment One results}

Crews were asked to perform fairly complex taxi maneuvers for various display and weather conditions. From Figure 6, it can be seen that the best navigational performance was with the Advanced HUD display concept regardless of the weather condition. The Advanced HWD display concept had 6 minor navigational errors, where the crew knew immediately that they made a mistake and informed the ground controller and requested instructions. However, for the Baseline and Intermediate HWD concepts, the crew didn't realize a mistake had been made. The crews continued on the wrong course unaware they were no longer on the cleared path. With the exception of the SA paired comparison result, there were no significant differences between the Baseline EMM and Intermediate HWD concepts. Pilots commented that the Intermediate HWD concept presented the taxi signage in head-up and familiar format.

When looking at the number of taxi incursion events, the greatest number occurred with the Advanced HUD concept while the least occurred with the Advanced HWD concept. The data implies that the Advanced HUD provides the best tactical information but fails to impart a strategic awareness. This result has been attributed in previous work to possible HUD cognitive capture and was observed at NASA Ames Research Center ${ }^{15}$. In contrast, the advanced HWD concept had the fewest number of taxi incursions.

For the nose-to-nose rare event scenario, all but 2 of the crews who had traffic displayed were able to avoid the nose-tonose situation. The rare event showed that having traffic displayed was a significant enhancement to the crew's situational awareness. Crews that avoided the nose-to-nose were able to notify ground of the traffic on their cleared path and ask for new instructions. The two crews that did not notice the traffic stated that the color of the traffic symbol made it difficult to see the traffic icon especially at large range scales. They also said it was hard to remember which scenarios had displayed traffic. Half of the data runs did not display traffic (Baseline and Intermediate HWD) and these runs were randomly assigned in the run sequence. Therefore, a follow-on second experiment was designed that addressed the readability/discernability of traffic.

\section{EXPERIMENT TWO: TAXI OPERATIONS WITH ADVANCED DISPLAYS, PHASE II}

From the rare event results of Experiment One, the traffic icons were found to be difficult to distinguish, particularly on the head-down display. In Experiment One, a brown color was used for traffic icons to conform with TCAS colorcoding standards for ground traffic. For Experiment Two, a cyan color was used to increase visibility. Further, the traffic icon sizes were scaled as a function of the range scale. The combination of these changes greatly increased traffic awareness in preliminary testing. In addition, the taxi director insert display on the advanced HWD concept was modified to improve readability and computational frame rates.

\subsection{Methodology}

\subsubsection{Evaluation pilots}

Twelve commercial flight crews (a captain and first officer) participated in the experiment. The 12 subjects for Experiment Two did not include anyone who had participated in Experiment One. Each flight crew flew for the same company to ensure crew coordination and cohesion with regard to surface operation procedures. The captains had an average of over 15000 flight hours with 29 years total flight time and the first officers had an average of over 9000 flight hours with an average of 26 years total flight time. Two-thirds of the captains required corrective lenses. The subjects were given a 45-minute briefing to explain the display concepts and the evaluation tasks. After the briefing, a 
45-minute training session was conducted to familiarize the subjects with the RFD simulator, the HUD, the HWD device, and the piloting task. Only the captain had a head-up display; the first officer had a head-down repeater display of the captain's head-up device. An eye dominance test was performed after the training briefing. Of the 12 subject captains, 11 were right eye dominant. The HWD was viewed with the right eye for all subjects. The HWD is compatible with eyeglasses. Following training, 2.5 hours of data collection was conducted. Twelve of the 24 scenarios from Experiment One were replaced with very short taxi routes, thus allowing for shorter data collection time. The total experiment time for each subject crew was approximately 4 hours.

\subsubsection{Evaluation task}

The evaluation task for Experiment Two was the same as Experiment One with the following exceptions: 1) A total of 25 different taxi scenarios were used in the study. 2) There was only one rare event scenario, the nose-to-nose scenario from Experiment One.

\subsubsection{Display concepts}

The display concepts (Fig. 7) for Experiment Two were the same as Experiment One with the following exceptions: 1) the Baseline display concept was replaced with a paper chart and existing cockpit displays, and 2) the Intermediate HWD concept was replaced with an Advanced EMM display (i.e., the Advanced EMM included iconic traffic, clearance information and the cleared route). There was no head-up display with either the Advanced EMM concept or the Paper Chart concept.

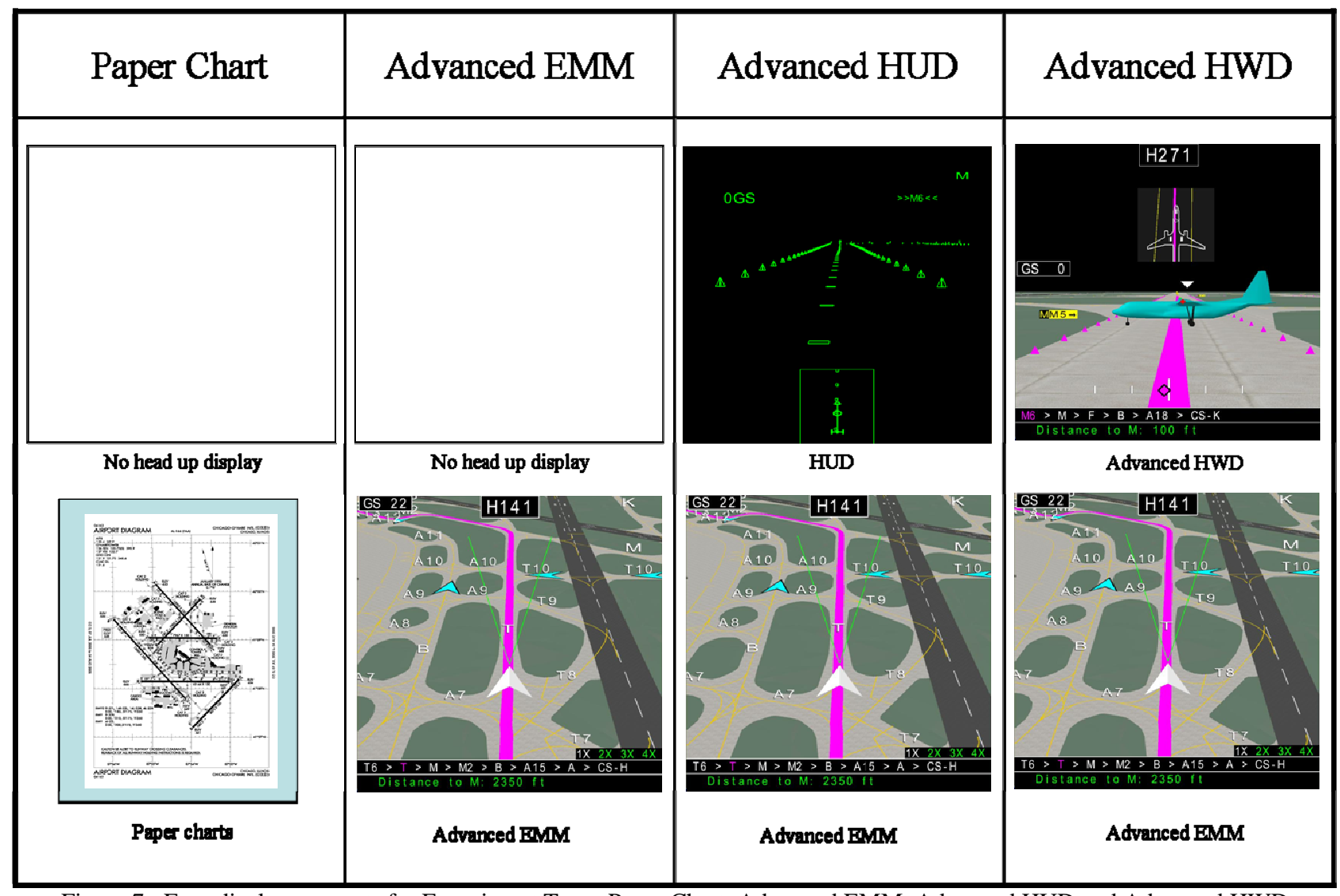

Figure 7: Four display concepts for Experiment Two: Paper Chart, Advanced EMM, Advanced HUD and Advanced HWD.

The traffic icons on the Advanced EMM and the Advanced HWD were modified to improve readability (Figs. 8 \& 9). The color was changed from brown to cyan. For the Advanced EMM, the traffic chevrons were scaled in size as a function of the range scale. As the range scale increased (zoomed out), the traffic chevron was increased in size to 
improve readability. Also, for the Advanced HWD, directional and strobe lights were added to the 3-dimensional traffic models.

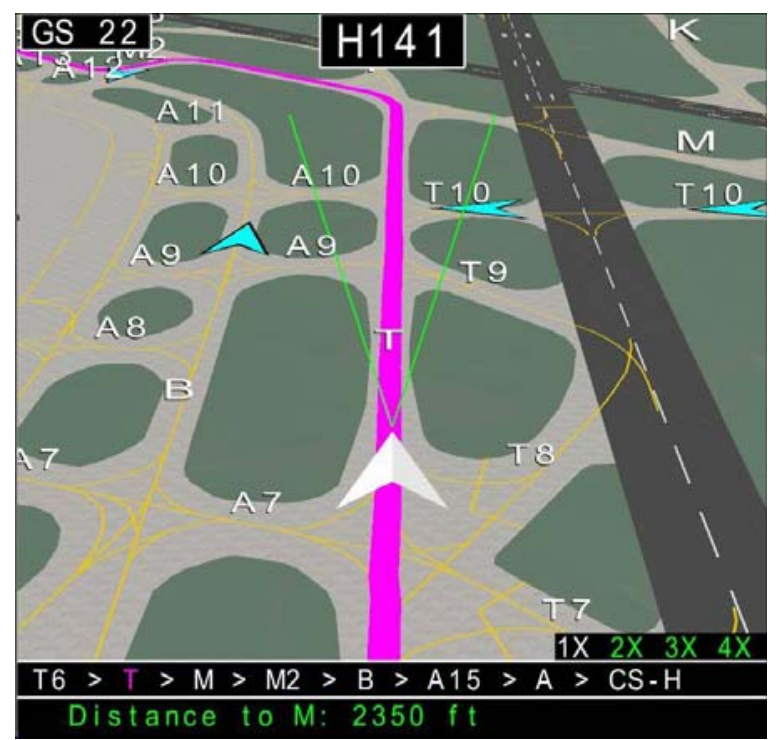

Figure 8. The Advanced EMM with traffic icons (blue chevrons), routing and clearance text.

In addition, the taxi director insert display on the Advanced HWD was modified to improve readability and frame computation speed. In Experiment One, the airport database was rendered in the insert window. For Experiment Two, the airport model was replaced with simple model of the runway and taxiway outlines. The result was a greatly simplified airport database, which improved rendering speed as well as readability by providing only essential information. The gain in computational speed allowed the virtual scene to be rendered within a $60 \mathrm{~Hz}$ frame. Additionally, the simplified airport database had greater contrast between the cleared route and the background, thus readability was improved in preliminary testing.

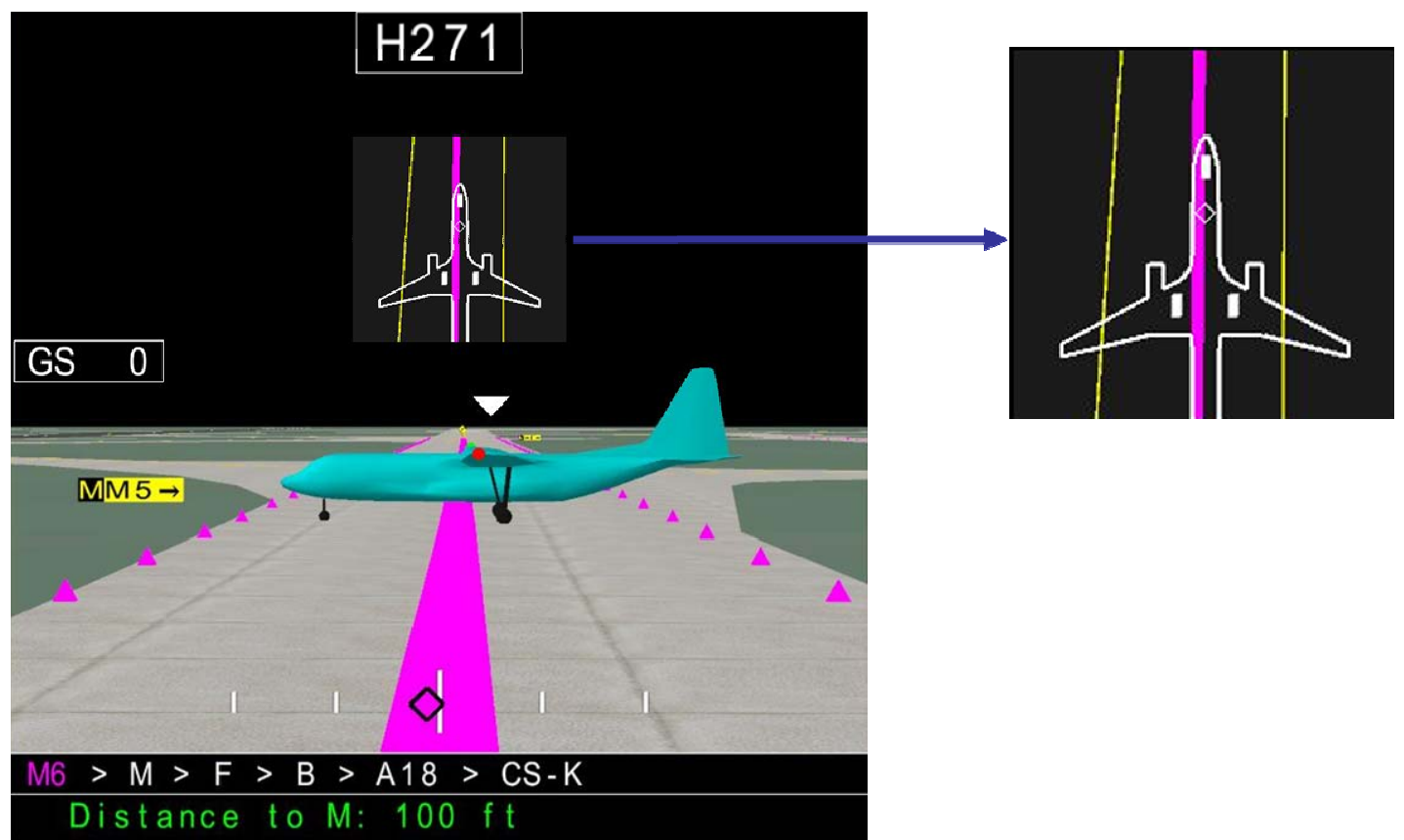

Figure 9. Advanced HWD in Experiment Two showing cyan traffic model and improved insert display. The higher contrast of the insert improved readability. 


\subsection{Experiment Two results}

\subsubsection{Quantitative data}

A Multi-Variate Analysis of Variance (MANOVA) Will's Lambda test revealed a significant main effect for display concept, $\mathrm{F}(9,585)=3.797, \mathrm{p}<0.0001$; and visibility condition, $\mathrm{F}(9,240)=5.170, \mathrm{p}<0.0001$. For display condition, subsequent tests of general linear model univariate effects showed significant effects for taxi speed $F(3,234)=3.389$, $\mathrm{p}$ $<0.05$; and RMS path error $\mathrm{F}(3,234)=8.063, \mathrm{p}<0.01$. No significant effects were found for time to taxi, $\mathrm{p}>0.05$.

For both RMS path error and taxi speed, post-hoc Student Newman-Keuls test reported two unique subsets: (1) Advanced EMM, Advanced HUD, and Advanced HWD (no significant differences between) which produced significantly lower RMS path error than the Baseline Paper condition; and (2) Baseline Paper (Fig. 10).

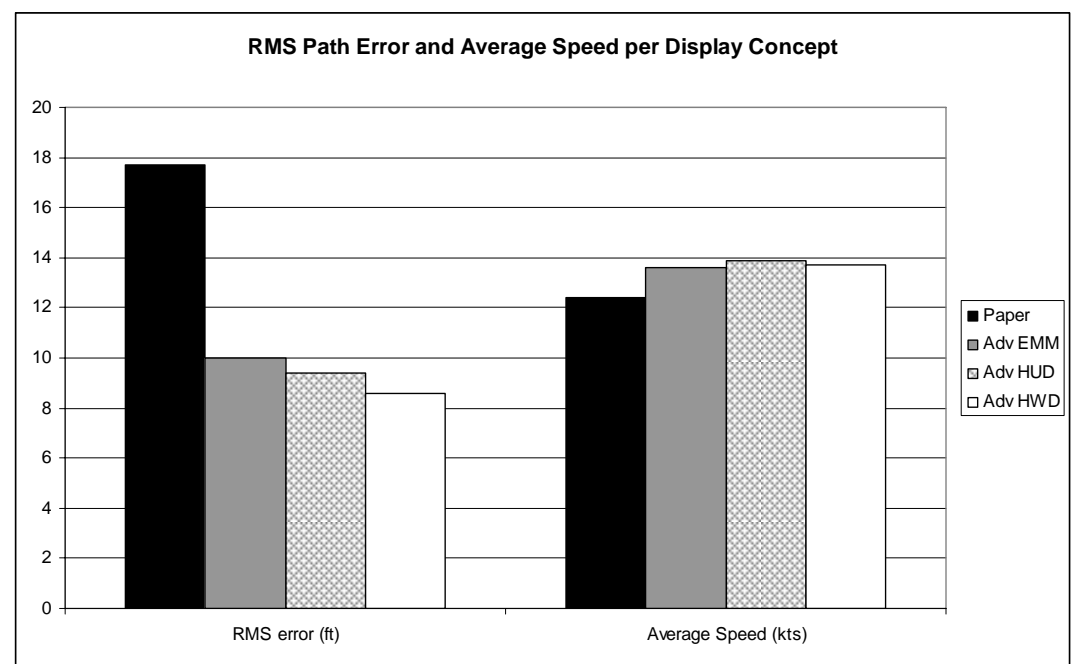

Figure 10. Taxi Speed and RMS Path Error per Display Condition for Experiment Two.

\subsubsection{Navigational errors}

As in Experiment One, navigational errors were divided into 2 categories: major and minor. Also as with Experiment One, a navigation error, which involved an incursion with other aircraft, was accounted for in a different measure and not included as a navigational error. A total of 14 navigational errors were made, where 7 were classified as major errors and 7 were classified as minor. Most of the major errors occurred with the Baseline Paper Chart concept. Figure 11 shows the navigational errors made per display concept and weather event (night VMC or day 700 RVR).

\subsubsection{Taxi incursions}

A taxiway incursion event was defined as a collision with another aircraft or making a turn in front of another aircraft and creating a close call. A total of 2 incursion events occurred one with the Advanced EMM concept and one with the Advanced HUD concept. 


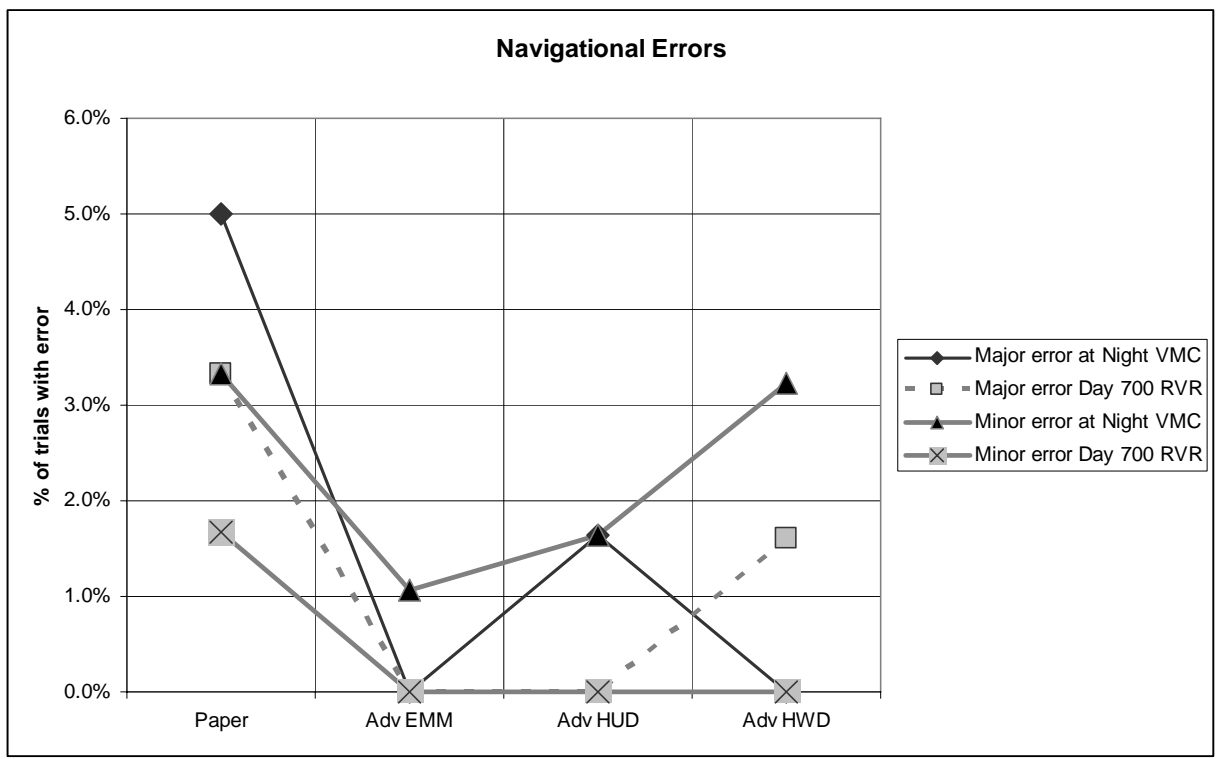

Figure 11: Navigational errors for Experiment Two.

\subsubsection{Rare event}

Experiment Two had one rare event scenario. The rare event was the final run of the day and created a nose-to-nose traffic incursion and was the same nose-to-nose scenario used in Experiment One. No subjects from Experiment One were used, thus subjects in Experiment Two were unaware of the scenario. Again, this event did not create a collision scenario but instead represented a more likely and common situation where two aircraft were nose-to-nose. Crews were given a ground controller instruction for them to turn onto a taxiway that was occupied by another aircraft (a small commuter jet). The visibility was reduced to 500 foot RVR for this scenario so that the traffic was difficult to see, but detectable, out-the-window.

The rare event display condition was evenly distributed between each of the 4 display concepts; therefore each of the 4 display concepts had 3 rare event data points. For the Baseline Paper Chart display concept, which did not have path or traffic information, all 3 crews got into a nose-to-nose condition. For the display concepts that had iconic traffic display (Advanced EMM, Advanced HUD and Advanced HWD), all crews were able to avoid the nose-to-nose situation.

\subsubsection{Qualitative data}

\subsubsection{Post-run}

\subsection{NASA TLX}

An ANOVA was performed for the dependent variable mental workload (task load index) from flight crew ratings on the NASA Task Load Index (NASA-TLX) scale. No significant differences were found, $\mathrm{p}>0.05$.

\subsection{SART}

An ANOVA was performed for the dependent variable situation awareness derived from flight crew ratings on the Situation Awareness Rating Technique (SART). SA = Understanding - (Demand - Supply). Analysis found a significant effect for display condition, $\mathrm{F}(3,15)=3.77, \mathrm{p}<0.05$. A Student Newman-Keuls test revealed two unique subsets: (1) Advanced HWD (135.25), Advanced HUD (142.16), or Advanced EMM (142.38) (no significant differences between) - Highest SA and (2) Baseline Paper condition (82.) - Lowest SA. 


\subsection{Taxi situational awareness questions}

Flight crews were administered a Likert post-run experimental questionnaire ( 1 to 5 scale; 1 = "not at all"; 5 = "very much") after each run which asked the pilots to rate the display conditions contribution to taxi efficiency, overall navigation awareness, route awareness of local controller clearance, route awareness of ground controller clearance, surface traffic awareness, directional awareness, and taxi safety. An ANOVA revealed significant effects for all dependent variables, $\mathrm{p}<0.05$. Post-hoc Student Newman-Keuls tests were performed on these dependent variables resulting in two unique subsets: (1) no significant differences between Advanced EMM, Advanced HUD, and Advanced HWD, and (2) Baseline Paper condition. Only flight crew ratings of display contribution to taxi efficiency were found not to be significant. Means for each dependent variable are presented in Table 2.

Table 2. Means for Post-Run Questionnaire by Display Condition.

\begin{tabular}{|c|c|c|c|c|c|c|c|}
\hline & $\begin{array}{c}\text { Taxi } \\
\text { Efficiency }\end{array}$ & $\begin{array}{c}\text { Navigation } \\
\text { Awareness }\end{array}$ & $\begin{array}{c}\text { Route } \\
\text { Awareness } \\
\text { (local) }\end{array}$ & $\begin{array}{c}\text { Route } \\
\text { Awareness } \\
\text { (Ground) }\end{array}$ & $\begin{array}{c}\text { Traffic } \\
\text { Awareness }\end{array}$ & $\begin{array}{c}\text { Direction } \\
\text { Awareness }\end{array}$ & Taxi Safety \\
\hline \hline Paper & 3.73 & 2.77 & 2.90 & 2.68 & 2.24 & 2.65 & 2.7 \\
\hline $\begin{array}{c}\text { Intermediate } \\
\text { HWD }\end{array}$ & 4.79 & 4.76 & 4.65 & 4.76 & 4.46 & 4.58 & 4.77 \\
\hline $\begin{array}{c}\text { Advanced } \\
\text { HWD }\end{array}$ & 4.76 & 4.76 & 4.70 & 4.73 & 4.61 & 4.57 & 4.70 \\
\hline $\begin{array}{c}\text { Advanced } \\
\text { HUD }\end{array}$ & 4.79 & 4.8 & 4.71 & 4.74 & 4.5 & 4.49 & 4.74 \\
\hline
\end{tabular}

\subsubsection{Post test}

\subsection{Paired comparisons}

A MANOVA statistical procedure was performed on four paired comparison scales administered to the captain and first officer of each flight crew; however, for brevity, only the captain's results are reported in this paper. The paired comparison scales asked the pilot to factorially evaluate each of the four display concept in comparison to one another on four constructs: Situation Awareness (SA-SWORD), Mental Workload (SWORD), Taxi Efficiency, and Taxi Safety. The analyses were conducted separately for captain and first officer responses. Significant results reported are at the $\mathrm{p}$ $<0.01$ significance level.

There was a significant main effect found for situation awareness, $F(3,30)=17.37$. A post-hoc test revealed that (a) Paper was rated significantly lower for situation awareness than the other three display concepts; (b) the Advanced EMM was rated significantly lower for Advanced HWD but not significantly different from Advanced HUD; and (c) no significant differences were found between the Advanced HUD and Advanced HWD concepts.

There was a significant main effect found for mental workload, $F(3,30)=366.69$. A post-hoc test revealed that Paper was rated significantly lower for mental workload than the other three display concepts. No other effects were found to be significant for mental workload.

There was a significant main effect found for taxi efficiency, $F(3,30)=25.76$. A post-hoc test revealed that (a) Paper was rated significantly lower for taxi efficiency than the other three display concepts; (b) the Advanced EMM was rated significantly lower for taxi efficiency than both the Advanced HUD and Advanced HWD; and (c) no significant differences between the Advanced HUD and Advanced HWD concepts.

There was a significant main effect found for taxi safety, $F(3,30)=4.9$. However, subsequent post-hoc pair-wise comparison (Bonferroni) failed to find any mean difference significant at the specified alpha level. 


\subsection{HWD usability and simulator sickness}

HWD specific issues of usability and simulator sickness were evaluated using post-test subjective questionnaires. These data are presented in SPIE Defense and Security Symposium paper 6557-31 by Bailey, et al in the Head/Helmet-Mounted Displays XII conference, April 2007.

\subsection{Discussion of Experiment Two results}

Experiment Two was designed to be a follow-on to Experiment One to fix the color of the displayed traffic and to evaluate additional display concepts to the baseline condition of airport paper map in order to fully complete the matrix of possible display comparisons. From Experiment One, even though traffic was displayed, some crews missed the displayed traffic and ended up in a "nose-to-nose" situation for the rare event scenario. For Experiment Two, none of the crews who had traffic displayed got into a nose-to-nose situation and, therefore, it appears likely that the color and size of the traffic icon was the main factor for the differing results from Experiment One.

The performance data showed that all of the advanced concepts provided better route accuracy and faster taxi speeds compared to paper charts alone. Though not significant, on average, pilots were able to complete the taxi route $15 \%$ faster with the advanced concepts compared to Paper. Previous T-NASA research reported taxi speed increases in the range of $16 \%$ to $26 \%{ }^{7}$.

One surprising result was that there were 2 taxiway incursion events in Experiment Two. These events occurred with the Advanced EMM and Advanced HUD conditions, respectively. Each of these events occurred despite the traffic being clearly represented on the head-down moving map display (Advanced EMM). These "near misses" were avoided through traffic detection made out-the-window. No such taxiway conflict events occurred with paper or the Advanced HWD conditions.

\section{GENERAL DISCUSSION OF RESULTS}

\subsection{Quantitative results}

The results with the Advanced HUD shown in this paper are similar to the results from previous surface operations research conducted by NASA Ames and NASA Langley. The performance data showed no significant differences between the Advanced EMM, Advanced HUD, and Advanced HWD display concepts for the dependent variables measured, but pilots taxied significantly faster and more accurately with these displays than when taxiing with just paper charts alone. In general, the advanced display concepts provided information (e.g., cleared route, ownship position, taxi guidance cues) enabling fast and efficient taxi. However, no quantitative performance differences were found in this study differentiating head-up versus head-down display concepts (i.e., when displaying the same or similar information). Additionally, the crews made significantly more navigation errors with the paper charts than with any of the other three advanced display concepts.

\subsection{Qualitative results}

The results of the paired comparisons showed that the addition of a head-up or head-worn display subjectively increased taxi efficiency compared to just having an advanced EMM alone. These results agree with past research conducted at NASA Ames Research Center demonstrating that the combination of head-up display and head-down display taxi concepts provides superior taxi performance.

From Experiment One, the 2-D head-down Baseline EMM and the 3-D head-up Intermediate HWD concepts displayed the same information but at different virtual camera perspectives. From the results, there were no significant differences between these two concepts except the Intermediate HWD was rated higher in SA than the Baseline EMM. Pilots commented that the Intermediate HWD presented the taxi signage in format that they were already familiar thus it was easy to interpret.

The NASA TLX results showed no significant differences for mental workload suggesting that the Advanced HWD display does not increase, nor reduce, mental workload demands compared to current navigation methods (i.e., using paper charts). Moreover, there were no differences found between the advanced display concepts further lending 
evidence that the introduction of an Advanced HWD concept would not increase cognitive and attentional demands for the flight crew.

The mental workload results are mirrored by the situation awareness post-run questionnaire and taxi situation awareness paired comparison results that also failed to show significant differences in perceived situation awareness between the advanced display concepts. These three display concepts were all rated significantly higher for situation awareness than taxiing with paper charts alone. When the subject captains were asked to rate their overall impressions of situation awareness, however, the SA-SWORD results did reveal that both the Advanced HUD and Advanced HWD provided significantly higher SA than the Advanced EMM concept. No significant differences were found for all ratings for all constructs between Advanced HUD and Advanced HWD suggesting that these two display concepts provide for equal amounts of perceived situation awareness, mental workload, taxi efficiency, and taxi safety.

\subsection{Taxiway conflicts}

There were fewer taxiway incursion events with the HWD than any other concept. Since all the relevant HUD information is contained in a $30^{\circ} \mathrm{H} \mathrm{x} 24^{\circ} \mathrm{V}$ display, pilots had their eyes out-the-window but may have been captured by the display symbology. This cognitive capture effect was much less evident with the HWD because the path came into view as the pilots choose to see it. Therefore, the pilot, when moving his/her head to scan for traffic, still has relevant navigation information in view. Consequently, the Advanced HUD concept had significantly more taxiway incursions than the Advanced HWD concept.

\subsection{Rare event results}

The rare event provided another measure of situational awareness for unexpected events. The experiments were designed to create mild fatigue by the final run to create line operation conditions that increase the likelihood of runway incursion situations. For the ATC error in which the controller gives a verbal instruction to turn the wrong way, it was clear that crews with a displayed route could detect the error before making the wrong turn. All crews that did not have a displayed route (i.e., Baseline EMM and Intermediate HWD) for this rare event made the wrong turn and did not realize the mistake until cross referencing with paper charts. Further, flight crews commented that the displayed route and EMM display provided significant situational awareness over paper charts.

The rare event involving the non-transponding aircraft was designed to examine cognitive capture effects. By providing routing, clearance information, and traffic, it was thought that such information might keep the crews head-down rather than eyes out. This rare event occurred late in the trials so that the crew was familiar with the display and the information displayed on it. The results showed that all crews were still mainly "eyes out" for traffic surveillance, which is consistent with their current training. Most crews were able to detect that the non-transponding traffic was not represented on the display(s).

The nose-to-nose rare event was designed to highlight traffic awareness by the crew. From Experiment One, two crews with the Advanced HWD display concept did not see the incurring traffic even though it was displayed both head up and head down. Both crews commented that the brown color of the displayed traffic was difficult to distinguish without concentrating on the displays. They commented that it was desired that traffic be detectable with a quick glance; however the traffic icons should not adversely clutter the displays. For Experiment Two, the traffic color and size was changed to improve readability. Subsequently, for Experiment Two, all crews with display concepts that had traffic information (Advanced EMM, Advanced HUD, and Advanced HWD) were able to avoid the nose-to-nose situation. As with the ATC rare event, crews had information available within the cockpit that contradicted the controller's clearance. In both situations, crews contacted the ground controller to resolve the discrepancy to avoid costly and potentially hazardous mistakes. Further, crews commented that the information presented on the HUD provided no additional benefit in detecting this rare event in contrast to the information available on the HWD (e.g., traffic). In other words, the Advanced HWD presented another source for displaying traffic information that supplemented information being presented on the Advanced EMM head-down display.

\subsection{Future research issues}

A significant body of research has shown that runway incursions can be mitigated or even prevented via flight deck alerting. For the experiments presented in this paper, however, the crew's situational awareness was the interest of 
study; therefore, alerting was not implemented. Alerting, in conjunction with these displays, would clearly add significantly to further enhancing the safety of surface operations. In addition to incursion alerting for a data-linked path, alerting could also be given when an aircraft is off-route, attempting to use a closed runway or taxiway, etc. Alerting provides critical cues when the crew (or controller) has already lost SA in such a way that creates a safety hazard. The goal of NASA HWD surface system is to enable the flight crew to be proactive and never lose surface SA. Future research will evaluate the additive effects of including such alerting algorithms, derived from the NASA Runway Incursion Prevention System research, to determine whether further safety enhancements to airport surface operations are possible.

One issue with HWD display is alignment. For these experiments, the HWD was aligned with the scene by displaying a grid pattern in the HWD and the same pattern in the out-the-window visuals. For actual operations, the alignment process would need to be quick, reliable and with a pre-determined degree of integrity and assurance in the alignment. Further, the HWD image stability and alignment must be maintained during operation. With a HUD, this bore-sighting procedure is done once and "hard-mounted" into the aircraft. The cost savings in weight for an HWD may be outweighed by the cost in developing a robust procedure for HWD alignment and image correlation.

For both experiments, the first officers had a repeater display of the head-up device (either the HUD or HWD). First officers commented that the repeat of the HUD did not provide any significant situational awareness. The HUD did not have the out-the-window image; therefore the first officer was unable to easily correlate the symbology to the scene. For the HWD repeater, first officers commented that the repeater was a distraction. The HWD repeater displayed all the captain's head movement, thus the image on the repeater was constantly changing. This highly dynamic image would tend to unnecessarily capture the first officer's attention. Essentially, early in the trials, the first officers ignored the repeater and commented that the Advanced EMM with routing, clearance and traffic information provided the essential information for surface operations in these experiments.

Another issue that NASA will be addressing in the future is obscuration of the outside world view by the pilot, in this "augmented reality" created by the HWD. For instance, semi-conformal display concepts, binocular/monocular displays, and clutter countermeasures will be explored in this area.

\section{CONCLUSIONS}

Overall, the results provide sufficient data to warrant the conclusion that an Advanced HWD has significant advantages over a HUD for enhancing taxiway conflict detection. There were a few limitations of the implementation of the HWD concept that may have reduced its full potential to demonstrate marked differences between the capabilities of the HUD and HWD concepts. Despite this, the taxiway conflict results suggest that an Advanced EMM alone, or in combination with a HUD, may not be sufficient to provide a total solution to the issue of runway incursions. With regard to all other results, no significant differences were found suggesting that the Advanced HUD and Advanced HWD are comparable to each other with regard to mental workload, taxi efficiency, taxi performance, and perceived taxi safety.

In addition to the efficiency and safety advantages of the advanced HWD, there are other considerations that argue for a HWD solution. The HWD provides potential weight savings that would have significant cost advantages to commercial airlines. Further, HUDs are designed for the flight regime, thus the $30^{\circ} \mathrm{H}$ by $24^{\circ} \mathrm{V}$ area is sufficient for flight but not necessarily for surface operations. On the ground, one of the main tasks of the crew is to survey all around the aircraft to avoid collisions with other airplanes or objects on the airport surface. This limitation was especially evident in the present experiment when the flight crew attempted turns because the path is only displayed as virtual turn flags in the HUD due to required over-steering.

The experiments revealed numerous future directions to better optimize and develop these concepts. One future direction involves the integration of enhanced vision sensor technology with the optimized HWD concept. Further, for these experiments, the routing and clearance information was relayed to the aircraft displays via a simulated controller data-link and implementation of conflict alerting. Currently, IIFDT/Crew-Vehicle Interface team is conducting research in using voice recognition technology to quickly and accurately enter routing information during read-back and possibly also, conducting analysis of the speech and airport information for route awareness and route / track analysis. 


\section{ACKNOWLEDGEMENTS}

The authors would like to acknowledge the CONITS team and the support staff of the RFD simulation facility. The CONITS software support team developed the Chicago database and the routing software. The RFD simulation support staff maintained the hardware and software for the RFD facility. All of this support was critical in obtaining the data in this report.

\section{REFERENCES}

1. Arthur III, J.J., Prinzel, L.J., Williams, S.P., \& Kramer, L.J. (2006). Synthetic vision enhanced surface operations and flight procedures rehearsal tool. in Enhanced and Synthetic Vision 2006, edited by Jacques G. Verly, Jeff J. Guell, Proceedings of SPIE Vol. 6226 (SPIE, Bellingham, WA, 2006) 62260I.

2. Jones, D. (2005). Runway Incursion Prevention System Testing at the Wallops Flight Facility. SPIE. In Proceedings of SPIE, Enhanced and Synthetic Vision 2005, Editor: Jacques G. Verly, Volume 5802, pp 47-58.

3. Foyle, D.C., Andre, A.D., McCann, R.S., Wenzel, E., Begault, D. \& Battiste, V. (1996). Taxiway Navigation and Situation Awareness (T-NASA) System: Problem, design philosophy and description of an integrated display suite for low-visibility airport surface operations. SAE Transactions: Journal of Aerospace, 105, 1411-1418.

4. Hooey, B.L. \&, Foyle, D.C., (2001). A Post-hoc Analysis of Navigation Errors During Surface Operations: Identification of Contributing Factors and Mitigating Solutions. Proceedings of the Eleventh International Symposium on Aviation Psychology. Columbus, $\mathrm{OH}$ : The Ohio Sate University.

5. McCann, R.S., Hooey, B.L., Parke, B., Foyle, D.C., Andre, A.D., \& Kanki, B. (1998). An evaluation of the Taxiway Navigation and Situation Awareness (T-NASA) system in high-fidelity simulation. SAE Transactions: Journal of Aerospace, 107, 1612-1625.

6. Byrne, M.D., \& Kirlik, A. (2005). Using Computational Cognitive Modeling to Diagnose Possible Sources of Aviation Error. International Journal of Aviation Psychology, 15(2), 135-155.

7. Hooey, B.L., Foyle, D.C., Andre, A.D. (2001). The design of aircraft cockpit displays for low-visibility taxi operations. In A.G. Gale (Ed.) Vision in Vehicles IX. Holland: Elsevier Science Publishers.

8. Foyle, D.C and Hooey, B.L., Improving Evaluation and System Design Through The Use of Off-Nominal Testing: A Methodology for Scenario Development. Proceedings of the 12th International Symposium on Aviation Psychology, pp. 397-402. Dayton, OH.

9. Hart, S. G., \& Staveland, L. E. (1988). Development of a multi-dimensional workload rating scale: Results of empirical and theoretical research. In P. A. Hancock \& N. Meshkati (Eds.), Human mental workload, 139-183. Amsterdam, The Netherlands: Elsevier.

10. Taylor, R. M. (1990). Situational awarenessrating technique (SART): The development of a tool foraircrew systems design. Situational Awareness in Aerospace Operations, AGARD-CP-478, 3-1 - 3-37.

11. Nelson, W.T., Bolia, R.S., Roe, M.M., and Morley, R.M.: Assessing Simulator Sickness In A See-Through HMD: Effects Of Time Delay, Time On Task, And Task Complexity. Paper presented at the IMAGE 2000 Conference, Scottsdale, AR, 10-14 July 2000.

12. Hennessy, R.T., Sharkey, T.J., Matsumoto, J.A., and Vorrhees, J.W.: Simulator Induced Alteration of Head Movements (SIAHM). paper presented at AIAA/AHS Flight Simulation Technologies Conference, Hilton Head Island, SC, Aug 24-26, 1992, Paper No. AIAA-1992-4134, pp. 29-36.

13. Kennedy, R.S., Lane, N.E., Berbaum, K.S. \& Lilienthal, M.G. (1993). Simulator Sickness Questionnaire: An enhanced method for quantifying simulator sickness. International Jour-nal of Aviation Psychology, 3:3 203-220.

14. Vidulich, M. A., and Hughes, E. R. (1991). Testing a subjective metric of situation awareness. InProceedings of the Human Factors Society 35th Annual Meeting (pp. 1307-1311). Santa Monica, CA:Human Factors Society.

15. Foyle, D.C., Hooey, B.L., Wilson, J.R., \& Johnson, W.A. (2002). SAE Transactions: Journal of Aerospace, 111, 647-658.

16. Melzer, J.E., Moffitt, K. (1997) Head Mounted Displays: Designing for the User. McGraw - Hill.

17. Kramer, L.J., Arthur, J.J. III, Bailey, R.E., \& Prinzel, L.J. III (2005). Flight Testing an Integrated Synthetic Vision System. SPIE. In Proceedings of SPIE, Enhanced and Synthetic Vision 2005, Editor: Jacques G. Verly, Volume 5802-01. 